\title{
Phosphorus-Doped Graphitic Carbon Nitrides in Situ Grown on Carbon Fiber Paper: Flexible and Reversible Oxygen Electrodes**
}

\author{
Tian Yi Ma, Jingrun Ran, Sheng Dai, Mietek Jaroniec and Shi Zhang Qiao*
}

\begin{abstract}
Flexible non-metal oxygen electrodes fabricated from phosphorus-doped graphitic carbon nitride nano-flowers directly grown on carbon fiber paper exhibit high activity and stability in reversibly catalyzing oxygen reduction and evolution reactions, which can be associated to $N, P$ dual action, enhanced mass/charge transfer and high active surface area. The performance is comparable to that of the state-of-the-art transition-metal, noblemetal and non-metal catalysts. Remarkably, the flexible nature of these oxygen electrodes allows their use in folded and rolled-up forms, and directly as cathodes in Zn-air batteries, featuring low charge/discharge overpotential and long lifetime.
\end{abstract}

$\boldsymbol{F}_{\text {lexible energy conversion and storage systems attract increasing }}$ attention due to their unique features such as shape conformability, light weight, small unit, etc., which enable their applications in foldable, bendable, portable and even wearable devices. ${ }^{[1]}$ However, the heavy, rigid and bulky configuration of oxygen electrodes in the current key renewable energy systems such as metal-air batteries, solar water splitting devices and fuel cells makes them far behind the requirement of flexibility. ${ }^{[2]}$ The design of flexible electrodes usually requires materials with three-dimensional (3D) architectures featuring excellent catalytic activity and good mechanical properties. ${ }^{[3]}$ Recently, carbon fiber paper (CFP), a soft current collector with 3D porous network, high electron conductivity and robust mechanical stability, has been employed as the replacement of conventional flat metal substrates (e.g. metallic foils, foams and meshes); and integrating CFP with functional materials such as metal oxides, phosphides, selenides and graphenes is feasible. ${ }^{[4]}$ Although considerable progress has been made to develop CFPbased electrodes for lithium-ion batteries and supercapacitors, ${ }^{[1 a, b]}$ there is still an enormous need for research on directly growing nonmetal catalytically active species on CFP to fabricate flexible oxygen electrodes for oxygen reduction and evolution reactions.

Oxygen reduction reaction (ORR) and oxygen evolution reaction (OER) are at the heart of rechargeable metal-air batteries and

[*] Dr. T. Y. Ma, J. R. Ran, A/Prof. S. Dai, Prof. S. Z. Qiao School of Chemical Engineering

The University of Adelaide, Adelaide, SA 5005 (Australia)

E-mail: s.qiao@adelaide.edu.au

Prof. M. Jaroniec

Department of Chemistry and Biochemistry

Kent State University, Kent, Ohio 44240 (USA)

[**] This work is financially supported by the Australian Research Council (ARC) through the Discovery Project programs (DP140104062 and DP130104459).

Supporting information for this article is available on the WWW under http://dx.doi.org/10.1002/anie.201xxxxxx. regenerative fuel cells. ${ }^{[2 a, 3 b]}$ Noble metals ${ }^{[5]}$ and transition metal oxides $^{[6]}$ are commonly utilized as the catalysts. However, high cost, scarcity and inferior durability of noble metals, and complicated fabrication of transition metal oxides with low conductivity largely prevent their practical applications. On the contrary, non-metal materials consisting of earth-abundant elements $(\mathrm{C}, \mathrm{H}, \mathrm{O}$ and $\mathrm{N})$ that act as catalytically active components have been recently recognized as a new class of low-cost and environmentally benign electrocatalysts. ${ }^{[7-9]}$ Among them, graphitic carbon nitrides $\left(\mathrm{g}-\mathrm{C}_{3} \mathrm{~N}_{4}\right)$ with ultrahigh $\mathrm{N}$ content (theoretically up to $60 \mathrm{wt} . \%$ ), stable and tailorable structure have been developed as efficient $\mathrm{ORR}^{[8]}$ and $\mathrm{OER}^{\left[{ }^{9]}\right.}$ electrocatalysts. Nevertheless, it is still urgent to further improve the activity of $\mathrm{g}-\mathrm{C}_{3} \mathrm{~N}_{4}$-based catalysts that are expected to outperform metal-containing ones. Doping $\mathrm{g}_{-} \mathrm{C}_{3} \mathrm{~N}_{4}$ is a promising route, which is stimulated by the fact that enhanced catalytic behavior (e.g. in photocatalysis) has been discovered by doping g$\mathrm{C}_{3} \mathrm{~N}_{4}$ with heteroatoms such as $\mathrm{B},{ }^{[10 \mathrm{a}]} \mathrm{P},{ }^{[10 \mathrm{~b}]} \mathrm{S},{ }^{[10 \mathrm{c}]}$ and $\mathrm{I}^{[10 \mathrm{~d}]}$ to alter its electronic and textural properties. However, heteroatom-doped g$\mathrm{C}_{3} \mathrm{~N}_{4}$ has scarcely been employed for oxygen electrochemistry.

Herein phosphorus-doped $\mathrm{g}-\mathrm{C}_{3} \mathrm{~N}_{4}\left(\mathrm{P}-\mathrm{g}-\mathrm{C}_{3} \mathrm{~N}_{4}\right)$ directly grown on CFP is designed as a flexible oxygen electrode (PCN-CFP), which represents the first $\mathrm{g}-\mathrm{C}_{3} \mathrm{~N}_{4}$-based non-metal ORR/OER bifunctional electrocatalyst. The flower-like $\mathrm{P}-\mathrm{g}-\mathrm{C}_{3} \mathrm{~N}_{4}$ composed of thin nanosheets is strongly coupled with CFP, rendering a 3D hybrid network with high $\mathrm{N}$ content and substantial P doping, which lead to excellent ORR and OER activity and durability, superior to its Pfree counterpart (CN-CFP), even comparable to Pt supported on CFP (Pt-CFP).

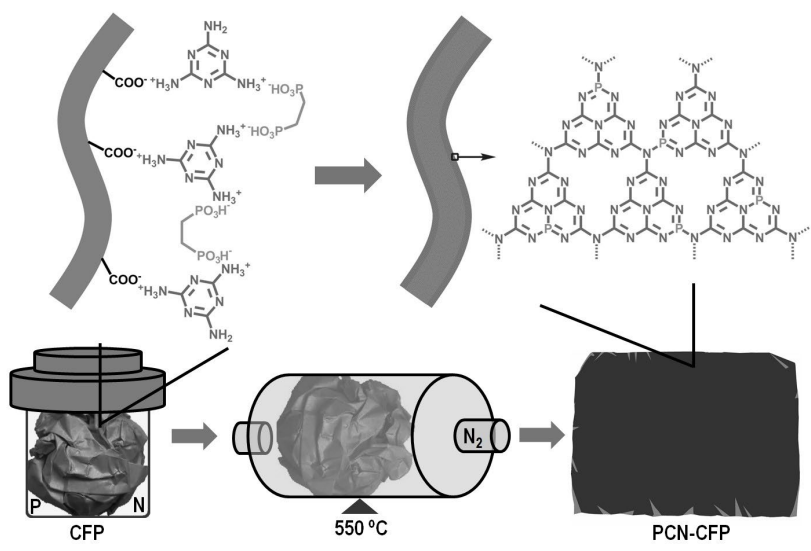

Scheme 1. Fabrication of $\mathrm{P}-\mathrm{g}-\mathrm{C}_{3} \mathrm{~N}_{4}$ nanostructure directly grown on CFP

The fabrication of PCN-CFP is shown in Scheme 1. Commercial CFP was first mildly oxidized, creating abundant functional groups (e.g. $\left.-\mathrm{COO}^{-}\right)$on the surface to enhance its interaction with basic melamine as the $\mathrm{N}$ source. Ethylene diphosphonic acid was utilized as the $\mathrm{P}$ source, due to its acid-base interaction with melamine that can facilitate cross-linking. After $\mathrm{N}$ and $\mathrm{P}$ sources assembling on 
CFP surface through a hydrothermal process, they further condensed into $\mathrm{P}-\mathrm{g}-\mathrm{C}_{3} \mathrm{~N}_{4}$ under heating treatment in $\mathrm{N}_{2}$ at $550{ }^{\circ} \mathrm{C}$, affording $\mathrm{PCN}-\mathrm{CFP}$ in different scales and shapes for direct electrochemical usage. The high decomposition temperature of ethylene diphosphonic acid $\left(>400{ }^{\circ} \mathrm{C}\right.$, Figure $\mathbf{S 1}$ in Supporting Information), being thermally stable until polycondensation of melamine starts, allows substantial and homogeneous $\mathrm{P}$ doping.
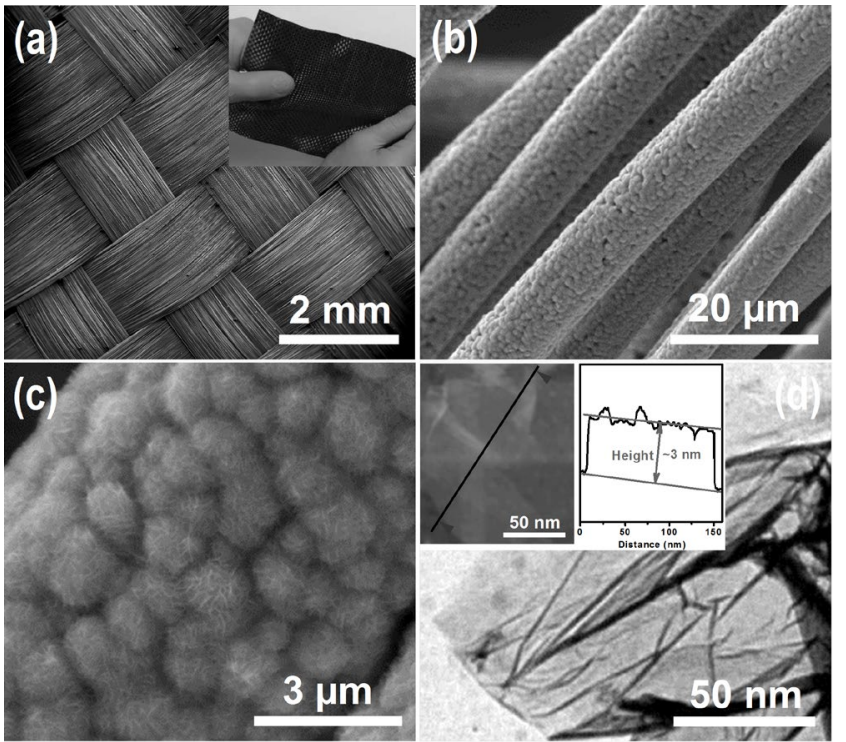

Figure 1. (a-c) SEM images and (inset in panel a) photograph of PCN-CFP. (d) TEM and (inset in panel d) AFM images with the corresponding height profile of $\mathrm{P}-\mathrm{g}-\mathrm{C}_{3} \mathrm{~N}_{4}$ nanosheets, collected from $\mathrm{P}-\mathrm{g}-\mathrm{C}_{3} \mathrm{~N}_{4}$ nano-flowers in PCN-CFP.

Large electrodes, e.g. a $10 \times 15 \mathrm{~cm}^{2}$ sized PCN-CFP of highly flexible shape (Figure 1a inset), can be prepared by this method. Scanning electron microscopy (SEM) images (Figures 1a, b) indicate PCN-CFP well maintains the fibrous morphology of CFP, which possesses a $3 \mathrm{D}$ network consisting of carbon fibers with diameter of $\sim 8 \mu \mathrm{m}$ (Figure S2). The textured surface of carbon fibers and the acid-base interaction between $-\mathrm{COOH}$ on CFP, basic melamine and ethylene diphosphonic acid (Scheme 1) facilitate adsorption of precursors and growth of $\mathrm{P}-\mathrm{g}-\mathrm{C}_{3} \mathrm{~N}_{4}$ nanostructure strongly attached to CFP. ${ }^{[4]}$ The magnified SEM image (Figure 1c) shows that flower-like $\mathrm{P}-\mathrm{g}-\mathrm{C}_{3} \mathrm{~N}_{4}$ densely grows on CFP rendering a porous framework. Transmission electron microscopy (TEM, Figures 1d, S3) and atomic force microscopy (AFM, Figure 1d inset) reveal that the flower-like $\mathrm{P}-\mathrm{g}-\mathrm{C}_{3} \mathrm{~N}_{4}$ nanostructure consists of interconnected nanosheets having thickness of $\sim 3 \mathrm{~nm}$ (equal to $\sim 9$ $\mathrm{CN}$ atomic monolayers). The nanosheets are formed due to the involvement of heteroatom motifs (i.e. ethylene diphosphonic acid) that interact with melamine and in situ alter its polymerization route $;{ }^{[11]}$ and the introduction of $\mathrm{P}$ (larger than $\mathrm{C}$ and $\mathrm{N}$ ) can disturb the graphitic structure of $\mathrm{g}_{-} \mathrm{C}_{3} \mathrm{~N}_{4}$, similar to the reported heteroatommediated "bottom-up" synthesis of $\mathrm{g}_{-} \mathrm{C}_{3} \mathrm{~N}_{4}$ nanosheets. ${ }^{[11]}$ On the contrary, only bulky g- $\mathrm{C}_{3} \mathrm{~N}_{4}$ particles exist on the surface of P-free $\mathrm{CN}-\mathrm{CFP}$ (Figure S4). Furthermore, the energy dispersive X-ray spectroscopy (EDS) elemental mapping images of PCN-CFP (Figure S3) confirm the uniform dispersion of N, P and C, indicating a homogeneous growth of $\mathrm{P}-\mathrm{g}-\mathrm{C}_{3} \mathrm{~N}_{4}$ on CFP.

PCN-CFP is constructed by strong coupling of $\mathrm{P}-\mathrm{g}-\mathrm{C}_{3} \mathrm{~N}_{4}$ and CFP, as evidenced by X-ray photoelectron spectra (XPS). The $\mathrm{N} \mathrm{1s}$ spectrum of PCN-CFP (Figure 2a), distinct from that of pure P-g$\mathrm{C}_{3} \mathrm{~N}_{4}$ (Figure S5), was deconvoluted into three components. The peak at $399.5 \mathrm{eV}$ is attributed to the bridging $\mathrm{N}$ atoms in $\mathrm{N}(-\mathrm{C})_{3}$ or
$\mathrm{N}$ bonded with $\mathrm{H}$ atoms, and the dominant peak at $398.4 \mathrm{eV}$ corresponds to the $\mathrm{sp}^{2}$-bonded $\mathrm{N}$ in triazine rings $(\mathrm{C}-\mathrm{N}=\mathrm{C}),{ }^{[10]}$ which splits to form an obvious new shoulder peak at $396.9 \mathrm{eV}$, caused by strong interaction between carbon fibers and $\mathrm{N}$ in $\mathrm{g}$ $\mathrm{C}_{3} \mathrm{~N}_{4} \cdot{ }^{[9,12]}$ The peak of $\mathrm{P} 2 \mathrm{p}$ binding energy is centered at $133.6 \mathrm{eV}$, which is typical for $\mathrm{P}-\mathrm{N}$ coordination, ${ }^{[13]}$ indicating that $\mathrm{P}$ most probably replaces $\mathrm{C}$ in $\mathrm{g}_{-} \mathrm{C}_{3} \mathrm{~N}_{4}$ to form $\mathrm{P}-\mathrm{N}$ bonds (Figure 2b). ${ }^{[10 b]}$ The XPS survey spectrum and high-resolution spectra of the most common metals in carbon fibers (e.g. Ni, $\mathrm{Co}$ and $\mathrm{Fe}$ ) indicate $\mathrm{PCN}$ CFP contains only $\mathrm{C}, \mathrm{N}, \mathrm{O}$ and $\mathrm{P}$ without detectable impurities on the surface (Figure S6), showing 13.2 wt.\% of $\mathrm{N}$ and 0.9 wt.\% of $\mathrm{P}$.
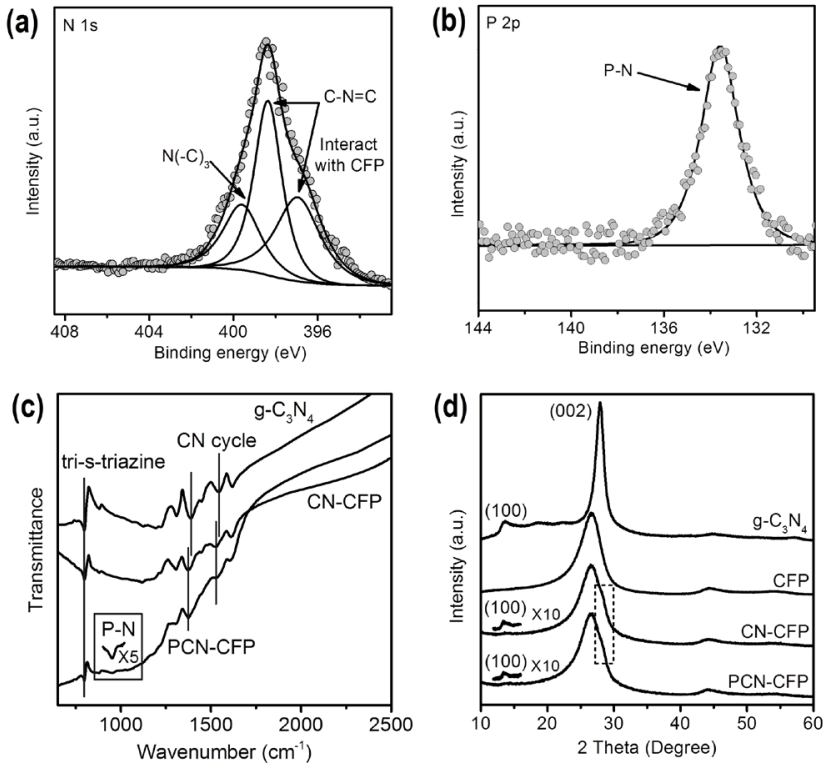

Figure 2. High-resolution XPS spectra of (a) N 1s and (b) $P$ 2p core levels in PCN-CFP. (c) FT-IR spectra and (d) XRD patterns of the synthesized materials.

The strong interaction between in situ grown $\mathrm{P}-\mathrm{g}-\mathrm{C}_{3} \mathrm{~N}_{4}$ and $\mathrm{CFP}$ is also proven by Fourier transform infrared (FT-IR) spectra (Figure 2c), in which the characteristic stretching modes of $\mathrm{CN}$ heterocycles in PCN-CFP between 900 and $1700 \mathrm{~cm}^{-1[10]}$ show apparent shifts as compared to pure g-C $\mathrm{C}_{3} \mathrm{~N}_{4}$, e.g. $1389 \rightarrow 1373 \mathrm{~cm}^{-1}$ and $1543 \rightarrow 1528$ $\mathrm{cm}^{-1}$. One newborn band at $\sim 950 \mathrm{~cm}^{-1}$ is attributed to $\mathrm{P}-\mathrm{N}$ stretching mode, ${ }^{[10 b, 13]}$ implying a substantial $\mathrm{P}$ incorporation, consistent with EDS and XPS results. The crystalline structure of $\mathrm{g}-\mathrm{C}_{3} \mathrm{~N}_{4}$ is well preserved in PCN-CFP, as evidenced by two typical signals on the $\mathrm{X}$-ray diffraction (XRD) pattern (Figure 2d) including the shoulder peak at $27.5^{\circ}(2 \theta)$ from $\mathrm{CN}$ graphitic-like layers and the low-angle peak at $13.3^{\circ}$ from in-planar repeated tri-s-triazine units. ${ }^{[10]}$

PCN-CFP can be directly used as the working electrode for both ORR and OER (Figure S7, Video S1) without extra substrates or binders. As shown by linear sweep voltammograms (LSVs), the pristine CFP exhibits negligible activities, while PCN-CFP affords an onset potential of $0.94 \mathrm{~V} v s$. reversible hydrogen electrode (RHE), and a half-wave potential $\left(E_{1 / 2}\right)$ of $0.67 \mathrm{~V}$ in ORR region, (Figure 3a), which are closer to those of Pt-CFP (onset potential $=0.99 \mathrm{~V}$, $E_{1 / 2}=0.80 \mathrm{~V}$ ) than those observed for the P-free counterpart CNCFP (onset potential $=0.90 \mathrm{~V}, E_{1 / 2}=0.63 \mathrm{~V}$ ). The more positive onset and half-wave potentials indicate a more facile ORR process initiated on PCN-CFP than that on CN-CFP. In OER region, PCNCFP affords a sharp onset potential at $1.53 \mathrm{~V}$, lower than that of CN$\mathrm{CFP}$ at $1.55 \mathrm{~V}$ and Pt-CFP at $1.59 \mathrm{~V}$ (Figure 3a). The oxidation current of PCN-CFP largely surpasses those of CN-CFP and Pt-CFP; and its operating potential to deliver a $10.0 \mathrm{~mA} \mathrm{~cm}^{-2}$ current density $\left(E_{\mathrm{j}=10}\right)$, a critical metric related to solar fuel synthesis, ${ }^{[14]}$ is $1.63 \mathrm{~V}$, much lower than those of CN-CFP $(1.69 \mathrm{~V})$ and Pt-CFP $(1.82 \mathrm{~V})$. 


\section{Communications}
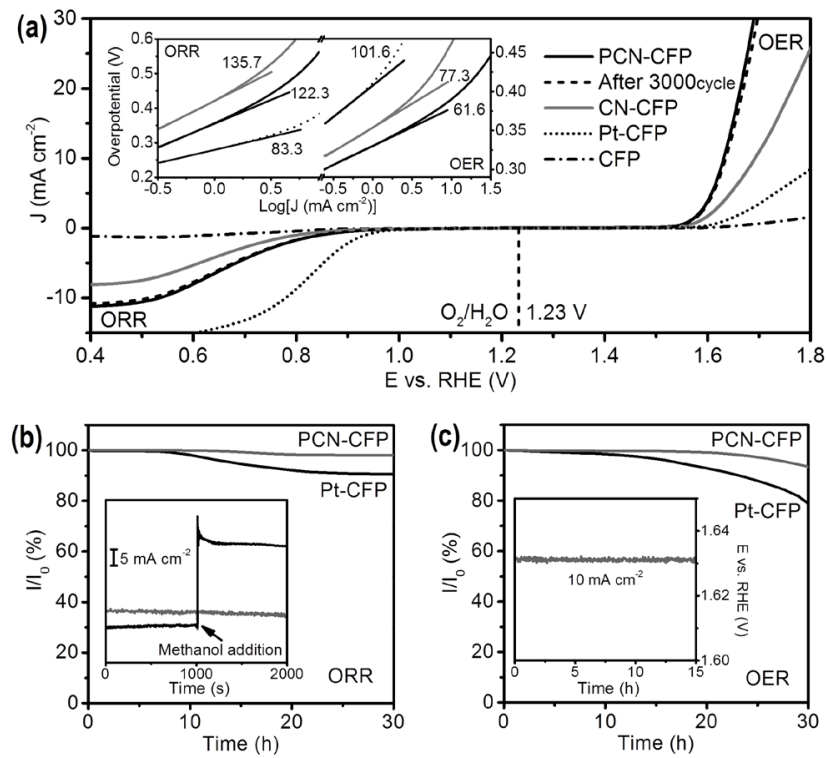

Figure 3. (a) LSVs and (inset in panel a) Tafel plots of PCN-CFP, CN-CFP, PtCFP and CFP in $\mathrm{O}_{2}$-saturated $0.1 \mathrm{M} \mathrm{KOH}$ solution at scan rate of $0.5 \mathrm{mV} \mathrm{s}^{-1}$. (b) ORR chronoamperometric response of PCN-CFP and Pt-CFP at a constant potential of $0.40 \mathrm{~V}$, and (inset in panel b) ORR chronoamperometric response after methanol addition. (c) OER chronoamperometric response of PCN-CFP and Pt-CFP at a constant potential of $1.63 \mathrm{~V}\left(E_{\mathrm{j}=10}\right)$, and (inset in panel c) OER chronopotentiometric response at a constant current density of $10.0 \mathrm{~mA} \mathrm{~cm}-2$.

The overall oxygen electrode activity and reversibility can be evaluated by the variance of OER and ORR metrics $\left(\Delta E=E_{\mathrm{j}=10}-\right.$ $E_{1 / 2)}{ }^{[5,6,14,15]}$ The smaller $\Delta E$ is, the closer the catalyst is to an ideal reversible oxygen electrode. PCN-CFP exhibits a $\Delta E$ of $0.96 \mathrm{~V}$, lower than that of CN-CFP $(1.06 \mathrm{~V})$ and Pt-CFP $(1.02 \mathrm{~V})$, also comparable to the highly active electrocatalysts including noblemetal (e.g. Pt/C,,$\left.^{[15 a]} \Delta E=0.94 \mathrm{~V} ; \mathrm{Ir} / \mathrm{C},{ }^{[15 b]} \Delta E=0.92 \mathrm{~V}\right)$, transitionmetal (e.g. $\mathrm{CaMn}_{4} \mathrm{O}_{x},{ }^{[15 b]} \Delta E=1.04 \mathrm{~V} ; \mathrm{Ni}_{x} \mathrm{O}_{y} / \mathrm{N}$-doped $\mathrm{C},{ }^{[15 a]} \Delta E=$ $0.93 \mathrm{~V})$, and non-metal materials (e.g. $\mathrm{N}$-doped graphene/carbon nanotube, $\left.{ }^{[15 \mathrm{c}]} \Delta E=1.00 \mathrm{~V}\right)$. A detailed comparison of various stateof-the-art bifunctional catalysts reported recently is presented in Table S1, further confirming the high catalytic activity and reversibility of PCN-CFP for ORR and OER.

PCN-CFP exhibits a Tafel slope value of $122.3 \mathrm{mV}$ decade $^{-1}$ in ORR region (Figure 3a inset), much lower than that of CN-CFP (135.7 $\mathrm{mV} \mathrm{decade}^{-1}$ ); while in OER region, the lowest Tafel slope value of PCN-CFP $\left(61.6 \mathrm{mV}\right.$ decade $\left.^{-1}\right)$ largely outperforms other control groups (CN-CFP: $77.3 \mathrm{mV}$ decade ${ }^{-1}$, Pt-CFP: $101.6 \mathrm{mV}$ decade $^{-1}$ ) and reported electrocatalysts (Table S1), suggesting its favorable reaction kinetics. Furthermore, by employing the rotating ring-disk electrode (RRDE) technique to investigate the reaction mechanism (Figure S8), the reversible ORR/OER process occurred on PCN-CFP is dominated by a desirable four-electron pathway with negligible formation of peroxide intermediates, i.e. $4 \mathrm{OH}^{-} \leftrightarrow \mathrm{O}_{2}$ $+2 \mathrm{H}_{2} \mathrm{O}+4 \mathrm{e}^{-}$. And the observed oxidation current can be fully attributed to OER with a high Faradaic efficiency of $98.7 \%$.

PCN-CFP shows a strong durability as revealed by the chronoamperometric response (Figure 3b), retaining $97.8 \%$ of the initial ORR current even after $30 \mathrm{~h}$, whereas Pt-CFP loses much more $(9.6 \%)$ of its initial current, indicating the apparent advantage in long-term stability of non-metal PCN-CFP over noble metals. A distinct methanol oxidation reaction occurs after methanol introduction in the case of Pt-CFP (Figure 3b inset), but the current density of PCN-CFP shows no obvious change, indicating its high selectivity to ORR with strong methanol tolerance. Moreover, PCN-
CFP exhibits a slight OER current attenuation of $6.6 \%$ after $30 \mathrm{~h}$ (Figure 3c) with no phase change or leaching of the active species (Figure S9), whereas Pt-CFP displays a 3.2 times larger current attenuation of $21.2 \%$. PCN-CFP can also afford a nearly constant operating potential at $1.63 \mathrm{~V}\left(E_{\mathrm{j}=10}\right)$ to deliver a $10.0 \mathrm{~mA} \mathrm{~cm}-2$ current density in $15 \mathrm{~h}$ (Figure 3c inset). Even at a high operating potential of $1.70 \mathrm{~V}$ (delivering a large current density of $\sim 35 \mathrm{~mA}$ $\mathrm{cm}^{-2}$ ), no peeling of the catalysts is observed (Video S1). Further, PCN-CFP is highly stable to withstand accelerated degradation with a scanning rate of $100 \mathrm{mV} \mathrm{s}^{-1}$ for 3000 cycles (dash line in Figure 3a), due to the strong coupling between $\mathrm{P}-\mathrm{g}-\mathrm{C}_{3} \mathrm{~N}_{4}$ and CFP.
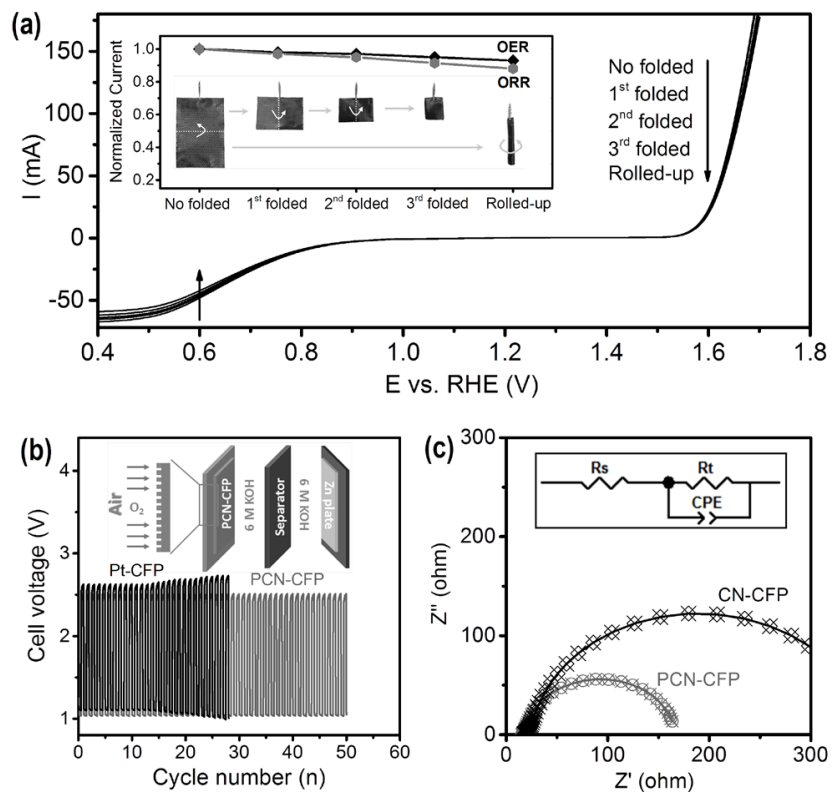

Figure 4. (a) LSVs and (inset in panel a) variations of the ORR (at $0.40 \mathrm{~V}$ ) and OER (at $1.63 \mathrm{~V}$ ) currents of PCN-CFP in different folded and rolled-up forms. The currents of the original unfolded electrode are normalized to 1. (b) Chargedischarge cycling curves and (inset in panel b) schematic configuration of $\mathrm{Zn}$-air batteries using PCN-CFP and Pt-CFP directly as the air cathodes. (c) EIS (recorded at $1.60 \mathrm{~V}$ ) of PCN-CFP and CN-CFP, and (Inset in panel c) the equivalent circuit diagram.

To fulfill the flexibility demand, the performance of PCN-CFP is measured in different folded and rolled-up forms (Figure 4a, Video S1). Even after folding the PCN-CFP electrode three times, $91.3 \%$ of the initial ORR current and $94.6 \%$ of the initial OER current were maintained; and the LSV of the folded PCN-CFP after 3000 potential cycles exhibits negligible current loss and morphology change (Figure S10), indicating the high cyclic stability of PCN$\mathrm{CFP}$ even in folded forms. The highly rolled-up PCN-CFP is capable of preserving $87.8 \%$ of the initial ORR current and $92.7 \%$ of the initial OER current, consistent with the smooth $\mathrm{O}_{2}$ bubble generation in different electrode forms observed in Video S1. The aforementioned facts reveal that PCN-CFP possesses high physical flexibility, stability and mechanical integrity towards folding and rolling-up treatments.

To demonstrate its feasibility in real energy devices, a Zn-air battery was constructed by directly using PCN-CFP as the air cathode (Figure $4 \mathbf{b}$ inset). As shown by the polarization curves for the assembled Zn-air battery (Figure S11), PCN-CFP affords a current density of $20 \mathrm{~mA} \mathrm{~cm}{ }^{-2}$ at $1.05 \mathrm{~V}$ during discharging and at $2.46 \mathrm{~V}$ during charging, outperforming that of Pt-CFP $(2.63 \mathrm{~V}$ during charging), which is consistent with LSVs obtained in the three-electrode system. More importantly, no obvious potential change is observed when PCN-CFP is used as the air cathode for over 50 charge-discharge cycles, whereas an apparent increase in both charge and discharge overpotentials is observed after 15 cycles 
Angewandte Communications

for Pt-CFP (Figure 4b). Therefore, the bifunctional PCN-CFP electrode is feasible in practical metal-air batteries, capable of reducing charging overpotential and enhancing cyclic stability.

Besides the $\mathrm{N}$-induced positively charged $\mathrm{C}$ atoms that are commonly considered as the active centers for both ORR and OER, ${ }^{[7-9]} \mathrm{P}$ species is also critical in promoting the electroactivity. When $\mathrm{P}$ is doped into $\mathrm{g}-\mathrm{C}_{3} \mathrm{~N}_{4}$, three of its five valence-electrons form covalent bonds with the $\mathrm{N}$ neighbors $(\mathrm{P}-\mathrm{N}$ bonds proven by XPS and FT-IR) to adopt a forced planar structure (Scheme 1), and the remaining lone pair can delocalize to the $\pi$-conjugated tri- $s$ triazine of $\mathrm{P}-\mathrm{g}-\mathrm{C}_{3} \mathrm{~N}_{4}$, leaving partially positively charged $\mathrm{P}^{+}$ centers, ${ }^{[10 b]}$ which act as the reinforcing active sites. New redox signals due to $\mathrm{P}^{+}$are visible on the differential pulse voltammograms (DPVs) (Figure S12a) and cyclic voltammograms (CVs) (Figure S12b) of PCN-CFP. Moreover, the heteroatom (e.g. P) doping can adjust electronic structure and enhance the delocalized $\pi$ bonds of $\mathrm{g}-\mathrm{C}_{3} \mathrm{~N}_{4},{ }^{[10,11]}$ consequently improving the conductivity and charge transfer. Accordingly, the semicircular diameter in electrochemical impedance spectrum (EIS) of PCN-CFP is much smaller than that of CN-CFP (Figures 4c, S13), due to a smaller contact and charge transfer impedance.

Furthermore, the strong coupling between $\mathrm{P}-\mathrm{g}-\mathrm{C}_{3} \mathrm{~N}_{4}$ and CFP facilitates the electron transfer between the two components, ${ }^{[8,9]}$ and the 3D nanostructure of PCN-CFP favors the smooth transport of reactants and products (e.g. $\mathrm{O}_{2}$, Video S1). More importantly, PCNCFP possesses a large catalytically active surface area, which was evaluated by the electrochemical double layer capacitance $\left(\mathrm{C}_{\mathrm{dl}}\right.$, Figure S14). $\mathrm{C}_{\mathrm{dl}}$ of PCN-CFP is confirmed to be $21.3 \mathrm{mF} \mathrm{cm}$, which is much higher than that of CN-CFP $\left.\left(\mathrm{C}_{\mathrm{dl}}=1.6 \mathrm{mF} \mathrm{cm}\right)^{-2}\right)$. Since $\mathrm{C}_{\mathrm{dl}}$ is proportional to the active surface area of electrocatalysts, ${ }^{[4]}$ the results demonstrate the formation of P-g- $\mathrm{C}_{3} \mathrm{~N}_{4}$ nano-flowers induced by $\mathrm{P}$ doping is more effective in enlarging the active surface area than pure $\mathrm{g}-\mathrm{C}_{3} \mathrm{~N}_{4}$ bulky particles.

In summary, $\mathrm{P}-\mathrm{g}-\mathrm{C}_{3} \mathrm{~N}_{4}$ consisting of thin nanosheets directly grown on CFP performs as a $3 \mathrm{D}$ foldable and rollable oxygen electrode. The outstanding activity, stability and reversibility of PCN-CFP for ORR and OER allow its direct use as the air cathode in $\mathrm{Zn}$-air batteries featuring low overpotential and long lifetime. This work will pave the way to a large variety of flexible electrodes constructed from non-metal polymeric and carbonaceous materials promoted by heteroatoms such as N, S, P and B.

Received: ((will be filled in by the editorial staff))

Published online on ((will be filled in by the editorial staff))
[1] a) X. Wang, X. Lu, B. Liu, D. Chen, Y. Tong, G. Shen, Adv. Mater. 2014, 26, 4763-4782; b) L. Li, Z. Wu, S. Yuan, X. B. Zhang, Energy Environ. Sci. 2014, 7, 2101-2122; c) W. Zeng, L. Shu, Q. Li, S. Chen, F. Wang, X. M. Tao, Adv. Mater. 2014, 26, 5310-5336.

[2] a) Z. Q. Peng, S. A. Freunberger, Y. H. Chen, P. G. Bruce, Science 2012, 337, 563-566; b) T. W. Kim, K. S. Choi, Science 2014, 343, 990-994.

[3] a) P. Zhang, J. Zhang, J. Gong, Chem. Soc. Rev. 2014, 43, 4395-4422; b) F. Y. Cheng, J. Chen, Chem. Soc. Rev. 2012, 41, 2172-2192.

[4] (a) D. Kong, H. Wang, Z. Lu, Y. Cui, J. Am. Chem. Soc. 2014, 136, 4897-4900; b) J. Q. Tian, Q. Liu, A. M. Asiri, X. P. Sun, J. Am. Chem Soc. 2014, 136, 7587-7590; c) L. Liu, Z. Niu, L. Zhang, W. Zhou, X. Chen, S. Xie, Adv. Mater. 2014, 26, 4855-4862; d) L. Shen, Q. Che, H. Li, X. Zhang, Adv. Funct. Mater. 2014, 24, 2630-2637.

[5] a) X. P. Han, F. Y. Cheng, Y. R. Zhang, J. G. Yang, Y. X. Hu, J. Chen, Adv. Mater. 2014, 26, 2047-2051; b) H. Over, Chem. Rev. 2012 112, 3356-3426.

[6] a) J. I. Jung, H. Y. Jeong, J. S. Lee, M. G. Kim, J. Cho, Angew. Chem. 2014, 126, 4670-4674; Angew. Chem. Int. Ed. 2014, 53, 4582-4586; b) F. Y. Cheng, J. Shen, B. Peng, Y. D. Pan, Z. L. Tao, J. Chen. Nat. Chem. 2011, 3, 79-84.

[7] a) D. W. Wang, D. S. Su, Energy Environ. Sci. 2014, 7, 576-591; b) Y Zhao, R. Nakamura, K. Kamiya, S. Nakanishi, K. Hashimoto, Nat. Commun. 2013, 4, 2390.

[8] a) J. Liang, Y. Zheng, J. Chen, J. Liu, D. Hulicova-Jurcakova, M. Jaroniec, S. Z. Qiao, Angew. Chem. 2012, 124, 3958-3962; Angew. Chem. Int. Ed. 2012, 51, 3892-3896; b) S. Yang, X. Feng, X. Wang, K. Müllen, Angew. Chem. 2011, 123, 5451-5455; Angew. Chem. Int. Ed. 2011, 50, 5339-5343.

[9] a) T. Y. Ma, S. Dai, M. Jaroniec, S. Z. Qiao, Angew. Chem. 2014, 126, 7409-7413; Angew. Chem. Int. Ed. 2014, 53, 7281-7285; b) J. Q. Tian, Q. Liu, A. M. Asiri, K. A. Alamry, X. P. Sun, ChemSusChem 2014, 7, 2125-2132.

[10] a) S. C. Yan, Z. S. Li, Z. G. Zou, Langmuir 2010, 26, 3894-3901; b) Y. Zhang, T. Mori, J. Ye, M. Antonietti, J. Am. Chem. Soc. 2010, 132, 6294-6295; c) G. Liu, P. Niu, C. Sun, S. C. Smith, Z. Chen, G. Q. Lu, H. M. Cheng, J. Am. Chem. Soc. 2010, 132, 11642-11648; d) G. Zhang, M. Zhang, X. Ye, X. Qiu, S. Lin, X. Wang, Adv. Mater. 2014, 26, 805-809.

[11] Z. Lin, X. Wang, Angew. Chem. 2013, 125, 1779-1782; Angew. Chem. Int. Ed. 2013, 52, 1735-1738.

[12] Q. Liu, J. Zhang, Langmuir 2013, 29, 3821-3828.

[13] H. Gu, Y. Gu, Z. Li, Y. Ying, Y. Qian, J. Mater. Res. 2003, 18, 2359 2363

[14] C. C. L. McCrory, S. Jung, J. C. Peters, T. F. Jaramillo, J. Am. Chem. Soc. 2013, 135, 16977-16987.

[15] a) J. Masa, W. Xia, I. Sinev, A. Zhao, Z. Sun, S. Grützke, P. Weide, M. Muhler, W. Schuhmann, Angew. Chem. 2014, 126, 8648-8652; Angew. Chem. Int. Ed. 2014, 53, 8508-8512; b) Y. Gorlin, T. F. Jaramillo, J. Am. Chem. Soc. 2010, 132, 13612-13614; c) G. L Tian, M. Q. Zhao, D. Yu, X. Y. Kong, J. Q. Huang, Q. Zhang, F. Wei, Small 2014, 10, 2251-2259.

Keywords: oxygen reduction • oxygen evolution • graphitic carbon nitride $\cdot$ nanostructure $\bullet$ phosphorus doping 


\section{Angewandte}

\section{Flexible electrode}

T. Y. Ma, J. R. Ran, S. Dai, M. Jaroniec, S. Z. Qiao* $1-5$

Phosphorus-Doped Graphitic Carbon Nitrides in Situ Grown on Carbon Fiber Paper: Flexible and Reversible Oxygen Electrodes

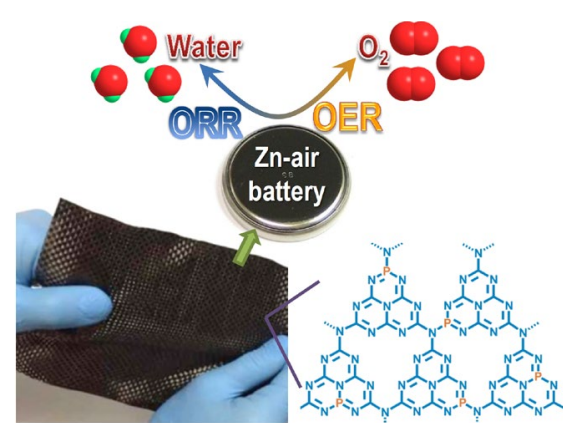

Flexible and reversible oxygen electrodes composed of nanostructured P-doped graphitic carbon nitrides grown on carbon fiber paper exhibit outstanding catalytic activity and stability towards both oxygen reduction and oxygen evolution reactions in different folded and rolled-up forms, due to N, P dual action and unique structural properties, which make them usable as efficient air cathodes in $\mathrm{Zn}$-air batteries. 